\title{
Selection in Dairy cattle
}

\author{
F. REINHARDT \\ Lehrstuhl für Tierzucht, D-8050 Freising-Weihenstephan
}

The culling process from one lactation to the next is described and quantified with a mathematical culling model proposed by ROBERTSON (1966). The conscious yield selection can be separated from involuntary natural wastage. The appropriate survival curves and parameters were calculated by a max. likelihood method described by FINNEY (1972). Selection for milk yield takes place mainly in the 1st lactation. In doing so the farmer gives the deviation from the mean more weight than the absolute milk yield. In later lactations the proportion of involuntary losses increases, so that selection cannot be as strong and efficient as earlier.

\section{Crossbreeding of cattle : effects on milk production}

\author{
B. SIMOVIC, M. MILOJIC, L. LAZAREVIĆ and M. PANIĆ \\ Faculty of Agriculture, University of Belgrade Zemun \\ 11080 Beograd, Yugoslavia
}

The comparative milk and milk fat production were under the experiment in the course of the entire and standard lactation, along with the FCM in the standard lactation. The Simmental breed was inseminated by the semen of the $F_{1}$ generation bulls (Simmental $\times$ Red Holstein) and the Black and White by the semen of Holstein Friesian breed. As control group were Simmental and Black and White breeds. With the crossbreeds of $\mathrm{R}_{1}$ generation from the first crossbreeding, higher yield of milk was determined along with higher butterfat yield, percentage of fat and FCM production in standard lactation. Absolute increase for the staded characteristics were $803 \mathrm{~kg}$ of milk, $33.7 \mathrm{~kg}$ butterfat, $0.08 \mathrm{p} .100$ of fat and $794 \mathrm{~kg}$ FCM.

Difference in butterfat production is very highly significant in milk and FCM production, high significant and nonsignificant in fat percentage. The crossbreds of $F_{1}$ generation produced, compared to the same-age contemporaries of the Black and White breed, for $877 \mathrm{~kg}$ more milk (23 p. 100), $24.7 \mathrm{~kg}$ buttefat (18 p. 100) and $722 \mathrm{~kg} \mathrm{FCM} \mathrm{(20} \mathrm{p.} \mathrm{100).}$ The percentage of fat with the crossbreeds was highly significantly lower in the entire and significantly lower in the standard lactation.

\section{Genetic parameters of the first three lactation records in Polish Lowland cattle}

\author{
A. ŻARNECKI and J. JAMROZIK \\ Department of Genetics and Animal Breeding \\ Academy of Agriculture, 30-059 Kraków, al. Mickiewicza 24/28, Poland
}

The heritabilities of milk and fat yields in the first lactation estimated by the REML method were .23 and .21 , respectively. Later lactations had heritabilities below .2. Very low heritabilities were obtained for the fat percentage in all lactations. Heritabilities estimated by Henderson's method 3 were slightly lower.

Genetic correlations between all lactations were in the range of .82 to .90 . 